\title{
Peran Granulasi dan Pengayaan Terhadap Peningkatan Efektivitas Kompos pada Sawi, Selada, Kangkung, dan Bayam
}

\author{
The Role of Granulation and Enrichment to Increase the Effectiveness of Compost on Green \\ Mustard, Lettuce, Kangkong, and Spinach
}

Yudi Sastro $^{1^{*}}$, Ikrarwati ${ }^{1}$, Suwandi ${ }^{2}$

Diterima 25 November 2011/Disetujui 1 Maret 2012

\begin{abstract}
This study aimed at determining the effect of granulation and compost enrichment to improve the effectivity of compost on green mustard, lettuce, kangkong, and spinach. The granulation treatments i.e without and with granulation and the enrichment using microbial cultures, the liquids from the rock phosphate fermentation, and the mixture of microbial cultures and the liquids from the rock phosphate fermentation were as treatments. The combinations of treatments were arranged using completely randomized block design with 20 replications. Variables observed were plant height, leaf number, fresh weight and dry weight. The data were analyzed using analysis of variance and followed by Duncan's Multiple Range Test. The results showed that there was no significant interaction between granulation with enrichment to improve the effectivity of compost on green mustard, lettuce, kangkong, spinach. The compost granulation treatment significantly increased the effectivity of compost on green mustard and lettuce, but not on kangkong and spinach. The granulation even decreased the compost effectiveness on spinach. The compost enrichments treatments significantly increased the effectivity of compost on green mustard, lettuce and spinach. The compost enrichments using the mixture of liquid fermentation medium of rock phosphate and microbial increased yield of green mustard and lettuce up to 48.4 and $60.1 \%$ respectively, while liquid fermentation medium of rock phosphate increased yield of spinach $75.0 \%$.
\end{abstract}

Key words: compost, granulation, enrichment, vegetable

\section{ABSTRAK}

Penelitian ini bertujuan untuk mengetahui pengaruh granulasi dan pengayaan terhadap efektivitas kompos pada sawi, selada, kangkung, dan bayam. Perlakuan penelitian terdiri atas perlakuan granulasi, yakni tanpa dan dengan granulasi, dan perlakuan pengayaan yang meliputi kultur mikroba, cairan media fermentasi batuan fosfat, dan campuran kultur mikroba dan cairan media fermentasi batuan fosfat. Kombinasi perlakuan diatur menggunakan Rancangan Acak Kelompok Lengkap dengan pengulangan sebanyak 20 kali. Peubah pengamatan meliputi tinggi tanaman, jumlah daun, dan berat segar serta berat kering tanaman. Data hasil pengamatan dianalisis menggunakan analisis varian dan dilanjutkan menggunakan Duncan Multiple Range Test. Hasil penelitian menunjukkan bahwa tidak terdapat interaksi nyata antara perlakuan granulasi dan pengayaan terhadap peningkatan efektivitas kompos pada sawi, selada, kangkung dan bayam. Perlakuan granulasi nyata meningkatkan efektivitas kompos pada sawi dan selada, namun tidak pada kangkung dan bayam. Perlakuan granulasi bahkan menurunkan efektivitas kompos pada bayam. Pengayaan nyata meningkatkan efektivitas kompos pada sawi, selada, dan bayam. Pengayaan kompos menggunakan campuran kultur mikroba dan cairan medium fermentasi batuan fosfat meningkatkan hasil sawi dan selada, masing-masing hingga 48,4 dan $60,1 \%$, sedangkan cairan medium fermentasi batuan fosfat meningkatkan hasil bayam sebesar $75 \%$.

Kata kunci: kompos, granulasi, pengayaan, sayuran

\section{PENDAHULUAN}

Peran penting kompos dalam mendukung pertumbuhan dan hasil tanaman telah dilaporkan oleh banyak peneliti, diantaranya Bulluck et al.
(2002), El-Ashry et al. (2008), dan El-Desuki et al. (2010). Kompos dilaporkan berperan dalam memperbaiki sifat fisika, kimia, maupun biologi tanah (El-Ghamry et al., 2001; Hargreaves et al., 2008; Saha dan Mishra, 2009). Namun

\footnotetext{
1) Balai Pengkajian Teknologi Pertanian Jakarta, email: yudis_bk12001@yahoo.com *penulis korespondensi

2) Balai Penelitian Sayuran Lembang-Jawa Barat
} 
demikian, pengaruh kompos antar perlakuan pemupukan sangat bervariasi yang diantaranya disebabkan oleh variasi bahan kompos dan praktek pemupukan di lapangan (Akanbi et al., 2007; Lakhdar et al., 2010; Joshi dan Vig, 2010). Selain itu, kandungan hara kompos relatif rendah dan bersifat ruah (bulky) dibandingkan pupuk kimia sehingga memerlukan takaran pemberian cukup besar guna memberikan pengaruh nyata pada tanaman.

Permasalahan di atas dipercaya dapat diatasi diantaranya melalui perlakuan pengayaan menggunakan bahan mineral serta inokulum mikroba fungsional. Pengaruh sinergisme pupuk organik dengan bahan mineral dan konsorsia mikroba di antaranya telah dilaporkan oleh Biswas (2008), Akhtar et al. (2009), dan Akbari et al. (2010). Pengayaan bahan kompos diharapkan akan meningkatkan kandungan hara dalam pupuk serta efektivitasnya dalam menyuplai hara untuk tanaman. Guna meningkatkan homogenitas bahan kompos dan pengkayanya, melindungi inokulum mikroba fungsional yang disertakan, serta memudahkan aplikasi pemupukan di lapangan maka kompos dan bahan pengkaya tersebut perlu disatukan dan digranulasi membentuk formula pupuk organik granular. Penelitian ini bertujuan untuk mengetahui pengaruh perlakuan pengayaan dan granulasi terhadap efektifitas kompos pada sawi, selada, kangkung, dan bayam.

\section{BAHAN DAN METODE}

\section{Bahan Penelitian}

Bahan penelitian yang digunakan meliputi : 1) contoh tanah Ultisol $\left(\mathrm{pH} \mathrm{H}_{2} \mathrm{O}: 5,9\right.$; Corganik: 1.47\%, N-total: 2.5\%; P-tersedia: 93 mg. $100 \mathrm{~g}^{-1} \mathrm{P}_{2} \mathrm{O}_{5}$; K: 9.0 mg. $100 \mathrm{~g}^{-1} \mathrm{~K}_{2} \mathrm{O}$; KTK: $25.3 \mathrm{me} 100 \mathrm{~g}^{-1}$; fraksi pasir: $2 \%$, debu $23 \%$, dan liat $75 \%$ ) diambil pada jeluk $0-25 \mathrm{~cm}$, dikeringanginkan, dan diayak lolos lubang saringan 2 $\mathrm{mm}$; 3) isolat Azotobacter vinelandii, Pseudomonas sp., Lactobacillus sp., Aspergillus niger; 4) batuan fosfat (P-air : $1.2 \%$; P-sitrat $2 \%$ : $4,6 \%, \mathrm{P}-\mathrm{HCl} 17,2 \%) ; 5)$ kompos (pH : 6.7; C/N : 9; C : 17.7\%; N-total : 2.0\%; $\mathrm{P}_{2} \mathrm{O}_{5}: 0.8 \% ; \mathrm{K}_{2} \mathrm{O}$ : $1.4 \%)$.

\section{Pembuatan Pupuk}

Inokulum mikroba merupakan campuran isolat Azotobacter vinelandii, Pseudomonas sp., dan Lactobacillus sp., masing-masing dengan kerapatan $10^{8}$ sel $\mathrm{ml}^{-1}$ kultur campuran. Sementara itu, hasil fermentasi batuan fosfat diperoleh dengan cara memfermentasi $100 \mathrm{~g}$ batuan fosfat menggunakan Aspergillus niger dalam media Pikovskaya cair selama 5 hari di atas mesin pengocok (shaker) berkecepatan 100 rotary per minute (rpm). Hasil fermentasi disaring menggunakan kerta saring Whatman 46. Kompos yang telah ditepungkan diperkaya zeolit dan kapur, masing-masing sebanyak 5\% (b/b). Selanjutnya dilakukan pengayaan sesuai perlakuan, yakni menggunakan kultur campuran mikroba, hasil fermentasi batuan fosfat, dan kombinasi keduanya. Pengayaan dilakukan dengan cara menyemprotkan bahan pengkaya yakni kultur mikroba atau hasil fermentasi batuan fosfat sebanyak $100 \mathrm{ml}$ per kilogram kompos. Pada perlakuan kombinasi inokulum mikroba dan hasil fermentasi batuan fosfat, bahan pengkaya yang ditambahkan masing-masing sebanyak 50 $\mathrm{ml}$ per kilogram bahan kompos. Selanjutnya campuran bahan digranulasi menggunakan mesin granulator membentuk pupuk granul dengan diameter rata-rata $3 \mathrm{~mm}$. Pengeringan granul dilakukan di dalam oven pada suhu $60^{\circ} \mathrm{C}$ selama 24 jam. Sementara itu, untuk perlakuan tanpa granulasi diperlakukan sama dengan perlakuan granulasi yakni diperkaya dan dikeringkan dalam oven pada suhu dan waktu yang sama dengan pupuk granul.

\section{Pengujian Tanaman}

Penelitian dilakukan di rumah kaca Balai Pengkajian Teknologi Pertanian Jakarta mulai April hingga Oktober 2010. Pengujian dilakukan dalam pot plastik yang berisi $3 \mathrm{~kg}$ contoh tanah dengan menggunakan sawi, selada, kangkung dan bayam sebagai tanaman uji. Percobaan diatur menggunakan Rancangan Acak Kelompok Faktorial 2x4 dengan 20 kali ulangan. Faktor pertama adalah perlakuan granulasi, meliputi tanpa granulasi dan granulasi. Faktor kedua adalah perlakuan pengayaan (enrichment) bahan pupuk, terdiri atas perlakuan tanpa pengayaan, pengayaan menggunakan campuran kultur mikroba Azotobacter vinelandii, Pseudomonas sp., dan Lactobacillus sp., masing-masing dengan kerapatan $10^{8} \mathrm{sel} . \mathrm{ml}^{-1}$, dan pengayaan menggunakan hasil fermentasi batuan fosfat menggunakan Aspergillus niger, dan pengayaan menggunakan kombinasi kultur mikroba dan hasil fermentasi batuan fosfat dengan perbandingan volume $1: 1$ 
Pemberian pupuk organik sebanyak 100 $\mathrm{g}$ per pot dilakukan tujuh hari sebelum tanam dengan cara ditebarkan dalam media tanam. Lima benih bayam dan kangkung ditanam langsung pada pot dan dijarangkan tujuh hari setelah tanam dengan menyisihkan satu tanaman per pot. Sementara itu, bibit sawi dan selada yang telah berumur tiga minggu dipindah-tanam langsung dalam pot. Peubah pengamatan terdiri atas tinggi, jumlah daun, berat segar dan berat kering tanaman, masing-masing diamati pada saat panen tanaman. Data hasil pengamatan diuji menggunakan analisis varian. Perbedaan antar perlakuan diuji menggunakan Duncan Multiple Range Test pada taraf uji 5\% (Gomez dan Gomez, 1984).

\section{HASIL DAN PEMBAHASAN}

Berdasarkan analisis statistik, tidak terdapat interaksi yang nyata antara perlakuan granulasi dan pengayaan kompos terhadap peubah pertumbuhan dan hasil sawi, selada, kangkung, dan bayam. Oleh sebab itu, pembahasan difokuskan pada pengaruh tunggal masing-masing perlakuan, yakni pengaruh granulasi dan pengayaan kompos terhadap pertumbuhan dan hasil masing-masing tanaman.

Secara tunggal, perlakuan granulasi kompos memberikan pengaruh yang berbeda pada sawi, selada, kangkung, dan bayam. Pertumbuhan dan hasil sawi meningkat dengan adanya perlakuan granulasi. Demikian juga halnya dengan selada, meskipun pengaruh pada selada tersebut lebih lemah dibandingkan sawi. Namun demikian, peningkatan tersebut tergolong kecil yakni berkisar 11,1-16,4\%. Berbeda dengan sawi dan selada, perlakuan granulasi pada kompos cenderung tidak memberikan dampak terhadap peubah pertumbuhan dan hasil kangkung. Granulasi kompos tersebut bahkan menurunkan tingkat pertumbuhan dan hasil bayam (Tabel 1, 2, 3, dan 4).

Sementara itu, perlakuan pengayaan secara umum meningkatkan pertumbuhan dan hasil sawi, selada, dan bayam. Namun demikian, pengaruh pengayaan tersebut beragam pada setiap peubah pengamatan di masing-masing tanaman. Selain itu, pengaruh pengayaan terlihat lebih kuat pada peubah hasil tanaman dibandingkan peubah pertumbuhan. Campuran kultur mikroba dan hasil fermentasi batuan fosfat merupakan bahan pengkaya yang memberikan respon terbaik terhadap hasil sawi dan selada (Tabel 1, 2, 3, dan 4).

Apabila dicermati terlihat bahwa perlakuan granulasi efektif pada sawi dan selada yang memiliki umur panen lebih panjang yakni 35 hari setelah pindah tanam. Sementara itu, kangkung dan bayam yang berumur relatif lebih pendek yakni hanya 21 hari, granulasi cenderung tidak berpengaruh bahkan menurunkan pertumbuhan dan hasil tanaman. Hal tersebut diduga disebabkan oleh dua hal. Pertama perlakuan granulasi diduga menyebabkan adanya penurunan luas permukaan kontak kompos dengan komponen tanah, mikroba, dan akar tanaman. Kedua, adanya pengaruh mobilisasi hara oleh mikroba, baik yang disertakan dalam pupuk maupun yang berasal dari tanah beberapa waktu setelah pemberian pupuk kompos. Kedua faktor tersebut secara langsung dan tidak langsung berpengaruh terhadap ketersediaan hara pada tanaman.

Tabel 1. Rata-rata tinggi, jumlah daun, bobot segar, dan bobot kering sawi pada setiap perlakuan granulasi dan pengayaan kompos

\begin{tabular}{lcccc}
\hline Perlakuan & $\begin{array}{c}\text { Tinggi tanaman } \\
(\mathrm{cm})\end{array}$ & $\begin{array}{c}\text { Jumlah daun } \\
\text { Granulasi : }\end{array}$ & $\begin{array}{c}\text { Bobot segar } \\
(\mathrm{g})\end{array}$ & $\begin{array}{c}\text { Bobot kering } \\
(\mathrm{g})\end{array}$ \\
$\quad$ - Tanpa granulasi & $17.3 \mathrm{~b}$ & $8.0 \mathrm{a}$ & $14.2 \mathrm{~b}$ & $1.8 \mathrm{~b}$ \\
$\quad$ - Granulasi & $18.3 \mathrm{a}$ & $8.5 \mathrm{a}$ & $16.6 \mathrm{a}$ & $2.2 \mathrm{a}$ \\
Pengayaan : & & & & \\
$\quad$ - Tanpa pengayaan & $17.1 \mathrm{a}$ & $7.6 \mathrm{~b}$ & $12.8 \mathrm{c}$ & $1.6 \mathrm{c}$ \\
$\quad$ - Kultur mikroba & $18.6 \mathrm{a}$ & $8.5 \mathrm{a}$ & $15.6 \mathrm{~b}$ & $1.9 \mathrm{~b}$ \\
$\quad$ - Hasil fermentasi batuan fosfat & $17.8 \mathrm{a}$ & $7.6 \mathrm{~b}$ & $14.2 \mathrm{~b}$ & $1.9 \mathrm{~b}$ \\
$\quad$ - Campuran kultur mikroba dan & $17.8 \mathrm{a}$ & $9.3 \mathrm{a}$ & $19.0 \mathrm{a}$ & $2.5 \mathrm{a}$ \\
$\quad$ hasil fermentasi batuan fosfat & & & & \\
\hline
\end{tabular}

Keterangan: Angka-angka yang diikuti huruf yang sama dalam satu kolom tidak berbeda nyata menurut DMRT 5\% 


\section{J. Hort. Indonesia 3(1):10-16. April 2012.}

Tabel 2. Rata-rata tinggi, jumlah daun, bobot segar, dan bobot kering selada pada setiap perlakuan granulasi dan pengayaan kompos

\begin{tabular}{lcccc}
\hline Perlakuan & $\begin{array}{c}\text { Tinggi tanaman } \\
(\mathrm{cm})\end{array}$ & Jumlah daun & $\begin{array}{c}\text { Bobot segar } \\
(\mathrm{g})\end{array}$ & $\begin{array}{c}\text { Bobot kering } \\
(\mathrm{g})\end{array}$ \\
\hline Granulasi : & & & & \\
$\quad$ - Tanpa granulasi & $15.7 \mathrm{a}$ & $8.0 \mathrm{a}$ & $19.0 \mathrm{~b}$ & $1.4 \mathrm{a}$ \\
$\quad$ - Granulasi & $15.5 \mathrm{a}$ & $8.5 \mathrm{a}$ & $21.2 \mathrm{a}$ & $1.5 \mathrm{a}$ \\
Pengayaan : & & & & \\
$\quad$ - Tanpa pengayaan & $14.2 \mathrm{c}$ & $7.6 \mathrm{c}$ & $16.8 \mathrm{c}$ & $1.1 \mathrm{~b}$ \\
- Kultur mikroba & $15.5 \mathrm{~b}$ & $8.5 \mathrm{~b}$ & $19.4 \mathrm{~b}$ & $1.6 \mathrm{a}$ \\
- Hasil fermentasi batuan fosfat & $15.8 \mathrm{~b}$ & $7.6 \mathrm{c}$ & $17.4 \mathrm{c}$ & $1.3 \mathrm{~b}$ \\
- Campuran kultur mikroba dan & $16.9 \mathrm{a}$ & $9.3 \mathrm{a}$ & $26.9 \mathrm{a}$ & $1.8 \mathrm{a}$ \\
$\quad$ hasil fermentasi batuan fosfat & & & & \\
\hline Keterangan: Angka-angka yang diikuti huruf yang sama dalam satu kolom tidak berbeda nyata menurut DMRT 5\%
\end{tabular}

Tabel 3. Rata-rata tinggi, jumlah daun, bobot segar, dan bobot kering kangkung pada setiap perlakuan granulasi dan pengayaan kompos

\begin{tabular}{lcccc}
\hline Perlakuan & $\begin{array}{c}\text { Tinggi tanaman } \\
(\mathrm{cm})\end{array}$ & Jumlah daun & $\begin{array}{c}\text { Bobot segar } \\
(\mathrm{g})\end{array}$ & $\begin{array}{c}\text { Bobot kering } \\
(\mathrm{g})\end{array}$ \\
\hline Granulasi : & & & & \\
$\quad$ - Tanpa granulasi & $30.9 \mathrm{a}$ & $11.9 \mathrm{a}$ & $19.5 \mathrm{a}$ & $1.5 \mathrm{a}$ \\
$\quad$ - Granulasi & $30.5 \mathrm{a}$ & $12.2 \mathrm{a}$ & $19.4 \mathrm{a}$ & $1.5 \mathrm{a}$ \\
Pengayaan : & & & & \\
$\quad$ - Tanpa pengayaan & $31.7 \mathrm{a}$ & $8.0 \mathrm{a}$ & $19.6 \mathrm{a}$ & $1.5 \mathrm{a}$ \\
- Kultur mikroba & $30.9 \mathrm{a}$ & $9.5 \mathrm{a}$ & $19.8 \mathrm{a}$ & $1.5 \mathrm{a}$ \\
- Hasil fermentasi batuan fosfat & $30.7 \mathrm{a}$ & $9.4 \mathrm{a}$ & $20.2 \mathrm{a}$ & $1.5 \mathrm{a}$ \\
- Campuran kultur mikroba dan & $29.3 \mathrm{a}$ & $9.6 \mathrm{a}$ & $18.0 \mathrm{~b}$ & $1.4 \mathrm{~b}$ \\
$\quad$ hasil fermentasi batuan fosfat & & & & \\
\hline Keterangan: Angka-angka yang dikuti huruf yang sama dalam satu kolom tidak berbeda nyata menurut DMRT 5\%
\end{tabular}

Tabel 4. Rata-rata tinggi, jumlah daun, bobot segar, dan bobot kering bayam pada setiap perlakuan granulasi dan pengayaan kompos

\begin{tabular}{|c|c|c|c|c|}
\hline Perlakuan & $\begin{array}{c}\text { Tinggi tanaman } \\
(\mathrm{cm})\end{array}$ & Jumlah daun & $\begin{array}{c}\text { Bobot segar } \\
(\mathrm{g})\end{array}$ & $\begin{array}{l}\text { Bobot kering } \\
(\mathrm{g})\end{array}$ \\
\hline \multicolumn{5}{|l|}{ Granulasi : } \\
\hline Tanpa granulasi & $8.8 \mathrm{a}$ & $9.1 \mathrm{a}$ & $12.9 \mathrm{a}$ & $1.0 \mathrm{a}$ \\
\hline Granulasi & $6.1 \mathrm{~b}$ & $9.2 \mathrm{a}$ & $6.7 \mathrm{~b}$ & $0.4 \mathrm{~b}$ \\
\hline \multicolumn{5}{|l|}{ Pengayaan : } \\
\hline Tanpa pengayaan & $16.8 \mathrm{a}$ & $8.4 \mathrm{a}$ & $8.0 \mathrm{c}$ & $0.6 \mathrm{c}$ \\
\hline Kultur mikroba & $13.2 \mathrm{a}$ & $8.2 \mathrm{a}$ & $7.2 \mathrm{c}$ & $0.5 \mathrm{c}$ \\
\hline Hasil fermentasi batuan fosfat & $17.1 \mathrm{a}$ & $8.8 \mathrm{a}$ & $14.0 \mathrm{a}$ & $1.0 \mathrm{a}$ \\
\hline $\begin{array}{l}\text { Campuran kultur mikroba dan hasil } \\
\text { fermentasi batuan fosfat }\end{array}$ & $14.4 \mathrm{~b}$ & 7.9 a & $10.0 \mathrm{~b}$ & $0.8 \mathrm{~b}$ \\
\hline \multicolumn{5}{|c|}{ Keterangan: Angka-angka yang diikuti huruf yang sama dalam satu kolom tidak berbeda nyata menurut DMRT 5\% } \\
\hline \multicolumn{2}{|c|}{$\begin{array}{l}\text { Orava et al. (2001) melaporkan bahwa } \\
\text { ketersediaan } \mathrm{N} \text { dari kompos yang dipeletkan nyata } \\
\text { lebih rendah dibandingkan tanpa dipeletkan. } \\
\text { Penurunan ketersediaan } \mathrm{N} \text { pada kompos yang }\end{array}$} & \multicolumn{3}{|c|}{$\begin{array}{l}\text { dipeletkan tersebut nyata menurunkan hasil Italian } \\
\text { ye-grass (Lolium multiflorum). Haggard dan Torr } \\
\text { (2006) melaporkan bahwa P tersedia dari pupuk } \\
\text { kandang ayam menurun secara nyata akibat }\end{array}$} \\
\hline
\end{tabular}


perlakuan pemeletan. Kuopanperti et al. (2001) membuktikan bahwa pengaruh pupuk abu kayu yang dipeletkan terhadap beberapa tanaman hutan lebih rendah dibandingkan pupuk abu kayu tanpa pemeletan.

Pengaruh positif granulasi pada sawi dan selada kemungkinan disebabkan oleh adanya masa inkubasi dan mineralisasi pupuk granul kompos akibat lebih lamanya umur panen. Efek inkubasi dan mineralisasi terhadap efektivitas pupuk kompos, mineral, dan inokulum mikroba telah dilaporkan, diantaranya oleh Sharpley dan Smith (1989); Schmidt et al. (1999); Tejada dan Gonzales (2003); Olayinka dan Adebayo (2004); Agyin-Birikorang et al. (2007); Agbenin et al. (2008).

Sementara itu, peningkatan efektivitas pupuk kompos akibat pengayaan hasil fermentasi batuan fosfat disebabkan oleh peningkatan keharaan kompos akibat proses pengayaan. Kpomblekou dan Tabatabai (1996), Vassilev dan Vassileva (2003) dan Vassileva et al. (2004) melaporkan bahwa hasil fermentasi batuan fosfat berupa P-terlarut air, kationkation basa khususnya $\mathrm{Ca}$ dan $\mathrm{Mg}$, asam-asam organik, enzim dan vitamin. Hal demikian diduga menyebabkan adanya peningkatan pertumbuhan dan hasil tanaman dengan adanya pengayaan hasil fermentasi batuan fosfat.

Adapun penurunan pengaruh pengayaan akibat penyertaan inokulum mikroba diduga disebabkan adanya efek mobilisasi hara oleh mikroba yang disertakan dalam kompos (Jonasson et al., 1996; 2005; Duah-Yentumi et al., 1998). Hal demikian dibuktikan dengan adanya penurunan pertumbuhan dan hasil bayam dan kangkung yang berumur relatif pendek. Oleh sebab itu, aplikasi kompos yang diperkaya dengan inokulum mikroba pada tanaman kangkung, bayam dan tanaman serupa memerlukan masa inkubasi tertentu, sehingga pengaruh imobilisasi hara oleh mikroba dapat dihindari.

\section{KESIMPULAN DAN SARAN}

\section{Kesimpulan}

Berdasarkan hasil penelitian di atas maka dapat disimpulkan bahwa :

1. Perlakuan granulasi dan pengayaan secara bersama-sama tidak memberikan pengaruh yang nyata terhadap peningkatan efektivitas kompos pada sawi, selada, bayam, dan kangkung.
2. Secara tunggal, perlakuan granulasi meningkatkan efektivitas kompos pada sawi dan selada dengan peningkatan hasil masing-masing mencapai $14.0 \%$ pada sawi dan $12.0 \%$ pada selada. Perlakuan granulasi tidak meningkatkan efektivitas kompos pada kangkung, bahkan efektivitas kompos yang digranulasi pada bayam lebih rendah dibandingkan tanpa granulasi.

3. Perlakuan pengayaan mampu meningkatkan efektivitas kompos pada sawi, selada, dan bayam. Pengayaan menggunakan campuran hasil fermentasi batuan fosfat dan inokulum mikroba meningkatkan hasil sawi dan selada, masing-masing sebesar 48.4 dan $60.1 \%$. Sementara itu, pengayaan menggunakan hasil fermentasi batuan meningkatkan hasil bayam sebesar $75 \%$.

\section{Saran}

Guna memperbaiki efektivitas, efisiensi, dan kemudahan dalam aplikasi kompos di lapangan maka perlakuan granulasi dan pengayaan kompos memiliki prospek untuk terus dikembangkan. Oleh sebab itu, kelemahan yang masih dijumpai dalam hal granulasi dan pengayaan masih perlu dipelajari lebih lanjut sehingga dapat tercipta suatu formula pupuk kompos yang lebih bernilai hara, berestetika, dan bernilai ekonomis tinggi dapat tercapai.

\section{DAFTAR PUSTAKA}

Adewumi, I.K., M.O., J.A. Adeptu, Y.L. Fabiyi. 2005.Planning of organic fertilizer industries for municipal solid waste management. J. App. Sci. Res. 1(3):285-291.

Agbenin, J.O., S.O. Lbitoye, A.S. Agbaji. 2008. Nutrient mineralization from deoiled Neem seed in savanna. Comunication in Soil Sci. Analysis 39(3-4):524-537.

Agyin-Birikorang, S., M. K. Abekoe, O.O. Oladeji. 2007. Enhancing the agronomic effectiveness of natural phosphate rock with poultry manure. Nutrient Cycling in Agroecosystem 79(2):113-123.

Akanbi, W. B., T. A. Adebayo, O. A. Togun, A. S. Adeyeye, O. A. Oianiran. 2007. The use of compost extract as foliar spray nutrient source and botanical insecticide in 
Telfaniera occidentalis. World J. Agric. Sci. 3(5):642-652.

Akbari, K. N., V. D. Vora, G. S. Sutaria, D. S. Hirpara, D. R. Padmani. 2010. Enrichment of compost by bio inoculants and natural mineral amandements. Asian J. Soil Sci. 5 (1):100-102.

Akhtar, A. J., H. N. Asghar, K. Shahzad, M. Arshad. 2009. Role of plant growth promoting rhizobacteria applied in combination with compost and mineral fertilizers to improve growth and yield of wheat (Triticum aestivum L.). Pak. J. Bot 4(1):381-390.

Biswas. 2008. Production of enriched compost. ICAR : A Science and Technology Newsletter. Vol. 14. No. 3. July-Sept.

Bulluck, L. R., M. Brosius, G. K. Evanylo, J. B. Ristaino. 2002. Organic and synthetic fertility amendments influence soil microbial, physical and chemical properties on organik and conventional farms. Appl. Soil Ecol 19: 147-160.

Duah-Yentumi, S., R. Ronn, S. Christenses. 1998. Nutrients limiting microbial growth in a tropical forest soil of Ghana under different management. App. Soil Ecol 8(1-3):19-24.

El-Ashry, S.M., S. Hanan, Siam, M.R. El-Moez. 2008. Ameliorative effect of organic fertilizers in the presence of mineral fertilizers on lettuce and sorghum yields and their components. Austr. J. Basic Appl. Sci 2(4):1246-1257.

El-Desuki, M., Magda M. Hafez, A. R. Mahmoud, and F. S. A. El-Al. 2010. Effect of organic biofertilizer on the plant growth, green pod yield, and quality of Pea. Int. J. Acad. Res 2 (1):87-92.

El-Ghamry, A.M., A. Subhani, E. M. El- Naggar. 2001. Efect of organic residues on microbial biomass in different Egyptian soils. Pakistan J. Biol. Sci 4 (12): 1479-1483

Gomez, K. A., A. A. Gomez. 1984. Statistical Procedures for Agricultural Research. John Willey and Sons, New York.
Haggard, B.E., G.S. Torr. 2006. Water Extractable Phosphorus in Raw, Heated, and Granulated Poultry Litters. Biological and Agricultural Enginering. University Arkansas. Faytteville-Arkansas.

Hargreaves, M.S.Adl, P.R. Warman. 2008. A review of the use of composted municipal solid waste in agriculture. Agric. Eco. Environ. 123:1-14.

Jonasson, S., P. Vestergaard, M. Jensen, A. Michelsen. 1996. Effect of carbohydrate amandement on nutrient partitioning plant, and microbial performance of a grasslandshrub. Nordic Society Oikos 75(2): 220226.

Jonasson, S., J. Castro, A. Michelson. 2005. Interactions between plants, litter and microbes in cycling of nitrogen and phosphorus in the artic. Soil Biol. Biochem 38(3):526-532

Joshi, R., A.P. Vig. 2010. Effect of vermicompost on growth, yield, and quality of tomato (Lycopersicum esculentum L.). African J. Basic App. Sci 2 (3-4): 117-123

Kpomblekou, K., Tabatabai, M.A., 1994. Effect of organic acids on release of phosphorus from phosphate rocks. Soil Sci. 158: 442-453

Lakhdar, A., R. Scelza, R. Scotti, M. A. Rao, N. Jedidi, L. Gianfreda, C. Abdelly. 2010. The effect of compost and sewage sludge on soil biologic activities in salt affected soil. R. C. Suelo Nutr. Veg. 10 (1): 40-47.

Olayinka, A., A. Adebayo. 2004. Effect of preincubated sawdust-based cowdung on growth and nutrient uptake of Zea mays (L.) and on soil chemical properties. Biol. Fertil. Soils 7(2):176-179

Orava, H., H. Kuopanportti, T. Tontti. 2006. Pelletizing waste compost and fly ash mixture to produce fertilizing material. Conference Proceeding of CHoPS. Finland.

Saha, R., V.K. Mishra. 2009. Effect of organic residue management on soil hydro-physical characteristics and rice yield in eastern Himalayan region, India. J. Sustainable Agric. 33(2):161-176. 
Schmidt, I.K., S. Jonasson, A. Michelsesn. 1999. Mineralization and microbial immobilization of $\mathrm{N}$ and $\mathrm{P}$ in artic soils in relation to season, temperature, and nitrogen. App. Soil Ecology 11(23):147-160.

Sharpley, A.N., S.J. Smith. 1989. Mineralization and leaching of phosphorus from soil incubated with surface-applied and incorporated crop residue. J. Environ. Qual. 18:101-105.

Tejada, M., J. L. Gonzalez. 2003. Effect of the application of a compost originating from crushed cotton gin residues on wheat yield under dryland conditions. European Jurnal of Agronomy 11(2):357-368.

Vassilev, N., M. Vassileva. 2003. Biotechnological solubilization of rock phosphate on media containing agro-industrial wastes. Appl. Microbiol. Biotechnol. 61: 435-440.

Vassileva, M., N. Vassilev, R. Azcon. 2004. Rock phosphate solubilization by Aspergillus niger on olive cake-based medium and its further application in a soil-plant system. Word J. Microbiol Biothec. 14(2):281-284. 